\title{
Michel Maslowski (Dir.), Religion et identité en Europe centrale
}

Paris, Belin, coll. « Europes Centrales », 2012, 346 p.

\section{Michael Löwy}

\section{(2) OpenEdition}

\section{Journals}

Édition électronique

URL : http://journals.openedition.org/assr/25558

DOI : $10.4000 /$ assr. 25558

ISSN : $1777-5825$

Éditeur

Éditions de l'EHESS

Édition imprimée

Date de publication : 30 décembre 2013

Pagination : 246

ISSN : 0335-5985

Référence électronique

Michael Löwy, « Michel Maslowski (Dir.), Religion et identité en Europe centrale », Archives de sciences sociales des religions [En ligne], 164 | 2013, mis en ligne le 11 mars 2014, consulté le 21 septembre 2020. URL : http://journals.openedition.org/assr/25558 ; DOI : https://doi.org/10.4000/assr.25558

Ce document a été généré automatiquement le 21 septembre 2020

(C) Archives de sciences sociales des religions 


\section{Michel Maslowski (Dir.), Religion et identité en Europe centrale}

Paris, Belin, coll. « Europes Centrales », 2012, 346 p.

Michael Löwy

\section{RÉFÉRENCE}

Michel Maslowski (Dir.), Religion et identité en Europe centrale, Paris, Belin, coll. «Europes Centrales », 2012, 346 p. 
1 Ce recueil de travaux très divers tente de cerner les rapports entre religion et nation, pas tellement au niveau de l'État nation que dans celui de la «nation culturelle», concept qui trouve son origine chez Herder et le romantisme allemand, et que Michel Maslowski reprend à son compte. La plupart des travaux sont classés par pays : le rôle du catholicisme et du protestantisme en Pologne (Michel Maslowski, Jadwiga WalaMenou, Kinga Siatkowska-Callebat), Hongrie (Ignac Romsics, Ildiko Szabo), les pays Tchèques (Daniel S. Larangé, Petr Kolar, Marie-Élisabeth Ducreux, Xavier Galmiche, Antoine Marès), la Slovaquie (Josanna Goszczynska), l’Ukraine (Teresa Chynczewska-Hennel); avec une section à part pour les Juifs.

2 On est frappé par le peu de place pour des

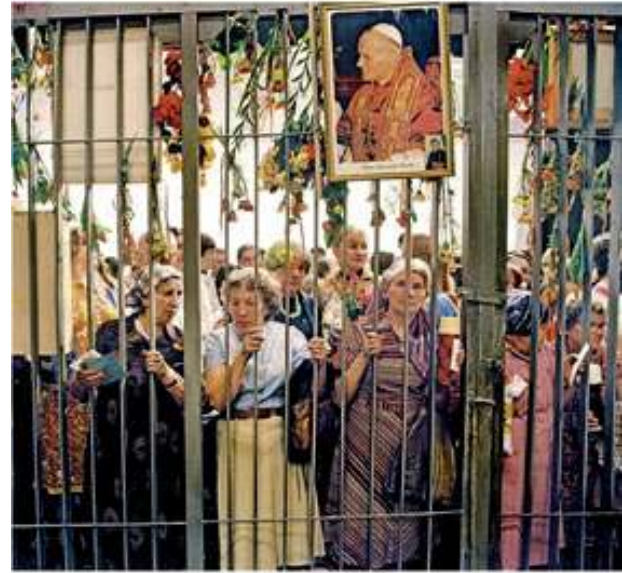

Belin: études comparatives, sauf une brève esquisse sur la Pologne et la Bohème (Jerzy Kloczowski) et une étude plus fournie de Patrick Michel, qui sert, en quelque sorte, de cadre général pour l'ensemble. On peut aussi s'interroger sur la pertinence du concept d'Europe centrale, qui désignait, au début $\mathrm{du} \mathrm{xx}^{\mathrm{e}}$ siècle, la Mitteleuropa germanique, mais semble, après 1989, substituer le terme, devenu désuet, «Pays de l'Est », sans qu'on puisse discerner une quelconque unité linguistique, culturelle ou historique entre ces pays.

3 Patrick Michel constate tout d'abord la grande diversité du rôle des Églises à l'époque du communisme officiel : opposition en Pologne, compromis avec le régime en Hongrie, etc. Mais quel qu'ait été ce rôle, toutes les Églises sont confrontées, après la sortie du communisme, avec la question du pluralisme, non seulement religieux mais aussi moral, politique et culturel. Une fois terminée la fiction unanimiste de l'unité de toute la nation, derrière l'Église, dans la résistance au régime en place, la pluralisation de l'espace public est inévitable. La tentation est grande, notamment en Pologne, d'imposer par en haut les "valeurs chrétiennes", sous des formes plus ou moins tolérantes, ou au contraire, comme dans le cas de Radio Maryja, par la disqualification des Juifs, des ex-communistes et autres francs-maçons.

4 L'identification entre la nation et la religion, dans le cas de la Pologne, remonte, comme l'observe Michel Maslowski, au XIx ${ }^{\mathrm{e}}$ siècle quand se forme, autour d'écrivains comme Adam Mickiewicz, éxilé à Paris, le «paradigme romantique du croire ». Après la défaite du soulèvement de novembre 1830 - condamné par le pape Grégoire XVI, qui soutient le Tsar russe - le nouveau paradigme identitaire va se cristalliser dans l'exil. Mickiewicz, son principal inspirateur, va proposer un prométhéisme chrétien, une renaissance morale et spirituelle universaliste, hors de l'Église institutionnelle. Quel est l'héritage de ce paradigme romantique, national et religieux à la fois ? Selon Maslowski, il peut prendre des formes nationalistes et antisémites dangereuses, instrumentalisant 
la religion à des fins politiques, comme dans Radio Maryja, ou alors des formes plus sociales, comme dans les écrits de Jean-Paul II. On peut s'interroger cependant si le Pape Woytila, la personnification même de l'Église comme institution, peut être effectivement l'héritier du paradigme romantique du croire de Mickiewicz, qui se situe clairement hors de l'institution...

Quelques mots sur les deux derniers essais, dédiés aux Juifs de l'« Europe centrale » - en fait, comme on verra, de l'Europe de l'Est, de la Pologne à la Russie. Dans un passionnant essai sur "religion et identité dans la culture yiddish socialiste (1890-1930) », Delphine Bechtel montre la prédominance, dans cette partie de l'Europe, d'options culturelles « nationalitaires ", autour de la langue yiddish et du socialisme, en contraste avec la confessionalisation du judaïsme en France et Allemagne. C'est le cas, bien entendu, du Bund, le grand parti ouvrier juif fondé dans l'Empire russe en 1897, partisan de valeurs laïques, qui préfère célébrer le Premier Mai plutôt que les fêtes juives. De même, les Sionistes Socialistes (Jacob-Wolf Latski-Bertoldi) qui s'opposent au "rabbinisme» et célèbrent la tradition juive d'athéisme (apikorses) ou d'hérésie (Spinoza) ; tout au plus certains non-croyants comme Moyshe Zilberfarb, fondateur du parti juif territorialiste SERP, admettent que la kehilah, la traditionnelle communauté juive religieuse, puisse, une fois sécularisée, devenir une forme laïque d'autoadministration juive. Les exceptions, c'est-à-dire les penseurs qui ont un rapport profond à la religion, sont rares: Khaym Zhitlovski, yiddishiste et adhérant du parti "populiste» russe SR, propose une "renaissance nationale-poétique de la religion juive" et définit le Shabbat comme une "fête sociale sacrée ", "la première manifestation de l'idéal socialiste moderne"; Isaac Nakhman Steinberg, lui aussi partisan des SR, combine adhésion stricte aux lois religieuses juives avec soutien à la Révolution d'Octobre. Il sera Commissaire du Peuple à la Justice pendant l'éphémère gouvernement de coalition entre les bolchéviques et les SR de gauche (décembre 1917mars 1918), et profitera de ce bref séjour au pouvoir pour abolir la peine de mort et libérer des centaines de prisonniers politiques...

6 Le dernier texte du recueil est consacré à l'écrivain juif polonais Bruno Schultz, assassiné par les nazis en 1942. Comme le montre très bien Malgorzata SmoragGoldberg, la prose poétique, "réaliste magique ", de Schultz fusionne le messianisme romantique de Mickiewicz avec celui de la tradition juive, dans un "bricolage" ironique et irrévérencieux avec les débris de textes sacrés juifs, où la place du Messie est occupée par l'Artiste moderne. 